IdeAs

Idées d'Amériques

Poètes et éditeurs : diffuser la poésie d'avant-garde américaine (depuis 1945)

\title{
Le discours de De Gaulle au balcon : préméditation ou improvisation?
}

Maurice Vaïsse

\section{OpenEdition}

Journals

Édition électronique

URL : https://journals.openedition.org/ideas/1910

DOI : $10.4000 /$ ideas. 1910

ISSN : 1950-5701

Éditeur

Institut des Amériques

Référence électronique

Maurice Vaïsse, « Le discours de De Gaulle au balcon : préméditation ou improvisation ? 》, IdeAs [En

ligne], 9 | 2017, mis en ligne le 12 juillet 2017 , consulté le 19 octobre 2022. URL : http://

journals.openedition.org/ideas/1910 ; DOI : https://doi.org/10.4000/ideas.1910

Ce document a été généré automatiquement le 19 octobre 2022.

\section{(2) $(\mathbb{Q} \Theta \Theta$}

Creative Commons - Attribution - Pas d'Utilisation Commerciale - Pas de Modification 4.0 International - CC BY-NC-ND 4.0

https://creativecommons.org/licenses/by-nc-nd/4.0/ 


\title{
Le discours de De Gaulle au balcon : préméditation ou improvisation?
}

\author{
Maurice Vaïsse
}

1 Palais de l'Élysée, mercredi 31 octobre 1962, le conseil des ministres ronronne; le ministre des Finances, Valéry Giscard d'Estaing, parle de l'exposition universelle de Mexico, dont il revient et dont il critique le pavillon français; il évoque la prochaine, qui aura lieu à Montréal en 1967. « De Gaulle (comme piqué par un taon) : (...) Il faut que la France, au cœur du Canada français, montre ce qu'elle est capable de faire (...) Les Canadiens français relèvent la tête et nous ne devons pas les laisser tomber ».

Et De Gaulle se rend lui-même à l'Exposition universelle en 1967, qu'il visite le mardi 25 juillet. Le dîner qu'il offre au Premier ministre et au gouvernement du Québec a lieu le soir même, au lendemain du fameux « discours du balcon », conclu par "Vive le Québec libre!».

3 Le contexte est capital : au cours de l'année 1967, il y a concurrence entre deux événements: l'exposition universelle d'un côté, mais de l'autre le centenaire de la confédération canadienne. Arrivé le 23, le Général repart le 26, sans se rendre à Ottawa, la capitale fédérale, comme c'était prévu. Comment en est-on arrivé là ? Essayons d'y répondre en posant trois questions : quelles étaient les conceptions du général de Gaulle à l'égard du Québec avant 1967? Comment expliquer l'évolution qui s'est produite entre 1940 et 1967 ? Enfin, le discours du balcon était-il prémédité ?

\section{Les conceptions du général de Gaulle à l'égard du Québec avant 1967}

4 Le Général avait-il un intérêt spécifique pour le Québec avant 1967 ? Dans un premier temps, il voit dans l'État canadien un allié des deux guerres mondiales. Quand il lance un appel le $1^{\text {er }}$ août 1940, il demande l'aide des Canadiens, sans prononcer le mot Québec. Lors des voyages qu'il effectue en juillet 1944 et août 1945, ses discours reflètent sa vision très unitaire du Canada « dans la fidélité au Commonwealth ». Après 
son retour au pouvoir en 1958, l'évolution est progressive et le voyage de 1960 ne dément pas sa vision d'un "État solide et stable qui trouve moyen d'unir deux communautés très différentes par l'origine, la langue, la religion ». C'est à la suite de ce déplacement au printemps 1960 que de Gaulle affirme son attachement sentimental à la Belle Province dans laquelle il voit un rameau de la communauté française. Or, l'année 1960 marque le début de la modernisation de la société québécoise et de la lente émergence d'un sentiment national, ce qu'on a appelé "la révolution tranquille »; d'ailleurs un nouveau gouvernement de la province dirigé par Jean Lesage demande l'ouverture d'une maison du Québec à Paris.

5 De Gaulle accueille très favorablement cette demande et insiste pour développer les rapports avec le Québec, même s'ils peuvent être désagréables pour le gouvernement d'Ottawa, qui reste un allié, y compris dans l'OTAN.

\section{Comment expliquer l'évolution qui s'est produite entre 1940 et 1967 ?}

6 Qu'est-ce qui explique l'évolution dans les années 1960, où se multiplient les contacts entre la France et le Québec? On peut distinguer quatre facteurs: d'abord la reconnaissance par de Gaulle de la fidélité d'un peuple qui envers et contre tous n'a jamais oublié sa patrie d'origine; ensuite la conviction que le droit des peuples à disposer d'eux-mêmes doit s'appliquer aussi au Québec; l'entourage joue un rôle important : bien que le Quai d'Orsay - par souci de ne pas bousculer le principe de noningérence dans les affaires intérieures d'un État - soit très réservé à l'égard de toute initiative à l'égard du Québec et multiplie les mises en garde, il existe un «lobby québécois ", groupe d'hommes déterminés qui comprend des diplomates ( Bernard Dorin, Jean Daniel Jurgensen, Gilbert Pérol, René de Saint Légier), des journalistes ( Pierre Louis Mallen, correspondant de l'ORTF à Montréal), des militants de la francophonie (Philippe Rossillon). Leur motivation est essentiellement culturelle et linguistique. Ils réussissent à influencer de Gaulle par l'information orientée qu'ils lui font parvenir. De la correspondance abondante reçue par le Général dans les semaines qui précèdent le voyage ressort une course de vitesse qui s'est engagée entre d'une part l'affirmation d'une identité nationale québécoise, d'autre part le déferlement de la civilisation américaine qui risque de submerger cette communauté québécoise avant qu'elle ait eu le temps de s'affirmer; enfin - en rapport avec ce facteur temps - la conviction du Général que "le temps lui était personnellement mesuré, et que le Québec ne disposait pas d'une période indéfinie pour accomplir son évolution». Au cours de son second mandat présidentiel, de Gaulle est obsédé par l'idée qu'il lui faut agir avant de disparaître, car après lui, aucun dirigeant n'osera se retirer de l'OTAN, prononcer le discours de Montréal, dire leur fait aux Israéliens.

\section{Le discours du balcon était-il prémédité ?}

7 Le discours du Balcon était-il prémédité? On sait que le Général préparait soigneusement ses discours, même ceux qui étaient improvisés. Comment a-t-il pu prendre position pour l'indépendance du Québec, reprenant à son compte l'expression du parti indépendantiste, adversaire du gouvernement de Daniel Johnson? Comment, 
lui si sourcilleux sur l'indépendance nationale, a-t-il pu commettre cette ingérence incroyable à l'égard d'un État indépendant et allié? Pour comprendre ces transgressions, il faut décortiquer la visite. Et d'abord, la réticence du Général à se rendre au Canada, parce qu'il y est allé souvent, mais il cède à l'insistance de certains personnages, dont le Premier ministre du Québec et le maire de Montréal, Jean Drapeau. Quand la décision est prise, elle répond à un objectif bien défini : il s'agit de visiter «le Canada français"; certes, le Général se rendra dans la capitale fédérale, mais cette visite n'aura qu'un caractère symbolique, et surtout pour éviter d'avoir à se rendre d'abord à Ottawa, il est décidé que le Général traversera l'Atlantique sur le croiseur Colbert. Enfin, la visite du Général correspond à un contexte de tension entre le gouvernement fédéral et le gouvernement français. Par exemple, ils s'affrontent sur l'itinéraire du voyage, de Gaulle refusant de commencer par la capitale fédérale, selon l'usage. Venu à Paris en mai 1967 pour inaugurer la maison du Québec à Paris, Daniel Johnson est reçu comme un chef d'État; et le Général parle à cette occasion du peuple québécois, « rameau du nôtre ».

Quand le Général débarque le dimanche 23 , l'atmosphère est exaltée ; il évoque «la francité » des Québécois; le lendemain lundi 24, le cortège parcourt les $270 \mathrm{~km} \mathrm{du}$ "Chemin du Roy ", de Québec à Montréal ; à chaque arrêt (Sainte Anne, Donnaconna, Repentigny, Trois Rivières, Louiseville, Berthier), de Gaulle prononce des discours dans une atmosphère de plus en plus enthousiaste et il reprend son thème central d'un "morceau du peuple français qui veut disposer de lui-même ». La foule porte des pancartes: France libre, Québec libre, Vive le Canada français, le Québec aux Québécois; de Gaulle fait chanter la Marseillaise. Des chorales chantent l'air de Gilles Vigneault: «Mon pays, ce n'est pas un pays, c'est l'hiver; mon jardin, ce n'est pas un jardin, c'est la plaine ", si bien que le cortège arrive en retard, en fin d'après-midi à Montréal, où il est reçu par le maire Jean Drapeau. La foule considérable s'impatiente et alors que le protocole avait prévu sobrement : «19h40, le président salue la foule de la terrasse ", le Général se saisit d'un micro et il prononce en sept minutes un discours, évoquant sur le ton de la confidence le souvenir de la Libération de Paris en août 1944, il promet le concours de la France, escompte en retour l'aide du Québec et il termine par : "Vive Montréal! vive le Québec ! vive le Québec... libre ! vive le Canada français et vive la France ! ». La stupéfaction est générale : avant de se laisser aller à une immense clameur, la foule hésite une demi-seconde. Selon le récit d'un ministre québécois, «nous nous regardâmes presque incrédules, estomaqués. Ce n'était pas possible. Le Général avait-il vraiment dit ce que nous avions cru entendre? »

9 À la suite du communiqué du gouvernement fédéral (25 juillet) déclarant « inacceptables» les déclarations du Général, celui-ci décide de ne pas se rendre à Ottawa et de rentrer sur Paris, non sans avoir visité l'Exposition et l'université de Montréal. Les réactions ont été très vives: le gouvernement canadien et les anglophones sont scandalisés de cette ingérence dans leurs affaires; le gouvernement québécois est très gêné, tandis qu'une partie de la population francophone applaudit à ce discours qui libère les énergies.

On a longtemps épilogué sur ce mot de trop: préméditation ou improvisation? On imagine mal que le Général ait pu se laisser aller; qu'il ait décidé de se rendre au Canada, alors qu'il hésitait; or il y va, donc préméditation! Mais le discours n'était absolument pas prévu; aucun projet n'existe et le micro lui-même est installé à la dernière minute ; l'atmosphère chaleureuse, les acclamations de la foule, « une sorte de 
choc auquel ni vous, ni moi ne pouvions rien ", ont pu jouer ainsi que le rapprochement entre la France libre et le Québec libre, formule qui figure sur de nombreux écriteaux du parti indépendantiste (RIN) tout le long du voyage et sur la place de l'hôtel de ville, donc improvisation!

11 Préméditation donc pour faire éclater au grand jour le problème du statut du Québec, mais improvisation dans l'expression. Bref, dans la formule "Vive le Québec libre », il ne s'agit pas d'une provocation calculée: elle est le fruit d'un concours de circonstances, tout en exprimant ce que pense profondément le Général, poussé à répondre à l'appel du peuple québécois.

Par la suite, et malgré l'avalanche de critiques à l'égard d'un président gâteux qui cette fois a dépassé les bornes, le Général - loin de regretter son coup d'éclat - persiste et signe; et, dans sa conférence de presse du 27 novembre, il célèbre «le mouvement d'affranchissement qui a saisi le peuple français d'Amérique... la France avait en ma personne le devoir sacré d'y répondre sans ambages et personnellement ». En cela, le discours du Balcon est dans la veine exacte de la démarche gaulliste d'une parole libre portée aux quatre coins du monde.

\section{BIBLIOGRAPHIE}

Anne et Pierre Rouanet, Les trois derniers chagrins du général de Gaulle, Grasset, 1980.

Maurice Vaïsse, La Grandeur, politique étrangère du général de Gaulle, 1958-1969, Fayard, 1998 ; Biblis, CNRS éditions, 2013.

\section{AUTEUR}

\section{MAURICE VAÏSSE}

Maurice Vaïsse est professeur émérite des universités (Sciences Po) et responsable de la publication des Documents diplomatiques français. Outre l'étude consacrée à la politique étrangère du général de Gaulle, il a publié - entre autres - La Puissance ou l'influence ? La France dans le monde depuis 1958, Fayard, 2008, ainsi que les relations internationales depuis 1945, Armand Colin, $15^{\circ}$ édition, 2017.maurice.vaisse@sciencespo.fr 